\title{
Synthesis of Film-Forming Photoactive Latex Particles by Emulsion Polymerization-Induced Self-Assembly to Produce Singlet Oxygen
}

\author{
Charlène Boussiron, Mickaël Le Bechec, Luca Petrizza, Julia Sabalot, Sylvie Lacombe,* \\ and Maud Save*
}

The design of photoactive polymer substrates producing singlet oxygen under visible light irradiation has great technological potential. Aqueous dispersion of novel photoactive core-shell particles was synthesized by surfactant-free reversible addition-fragmentation chain transfer (RAFT) emulsion polymerization of $n$-butyl acrylate. The surface of the nanoparticles is directly decorated thanks to the polymerization-induced self-assembly process using a hydrophilic macromolecular chain transfer agent (macro-CTA) functionalized with the organic photosensitizer. The macro-CTA was synthesized by statistical copolymerization of acrylic acid and 2-Rose Bengal ethyl acrylate (RBEA) at $80^{\circ} \mathrm{C}$ mediated with 4-cyano-4-[(dodecylsulfanylthiocarbonyl)sulfanyl]pentanoic acid. Monitoring polymerization kinetics of RAFT polymerization highlights that increasing amount of RBEA induces retardation, still more pronounced when using the vinylbenzyl Rose Bengal comonomer. The present work provides insight into the quantum yield of singlet oxygen production in water $\left(\Phi_{\Delta}=0.2-0.6\right)$ for the three types of synthesized polymers (hydrophilic polymer, latex particles, and polymer film). The photoactive core-shell latex particles enabled the easy preparation of photoactive polymer film by simple casting.

oxygen, ${ }^{[3]}$ induces specific oxidation reactions of organic molecules to produce, for instance, pharmaceutical ingredients like artemisinin. ${ }^{[1]}$ Immobilization of photosensitizers on solid substrates improves their handling, recyclability, stability, and facilitates purification steps to remove photocatalyst from reactants in fine chemistry. Also, there is an increasing demand to develop coatings reducing microbial contamination, particularly in healthcare or food packaging. Organic photosensitizers are recognized as light activated antimicrobial agents since the produced singlet oxygen is the major agent of cell injury by oxidation of the cell wall. ${ }^{[5]} \mathrm{A}$ wide variety of inorganic materials have been developed as substrates for organic photosensitizers but polymers have increasingly gained interest for their versatility and processability. A covalent anchorage is advantageous to limit any leaching issue of photosensitizer in the surrounding environment.

Waterborne latexes synthesized by emulsion polymerization, widely present in the coating industry for different applications ranging from waterborne paints, inks, adhesives, paper coating, protective coating or binders for food packaging, and textiles, elicit increasing interest for production of high added value innovative products. Production of singlet oxygen $\left({ }^{1} \mathrm{O}_{2}\right)$, a selective reactive oxygen species (ROS) by irradiation under visible light of organic photosensitizers (Sens), has attracted increasing interest in the fields of fine chemistry, ${ }^{[1]}$ photo-decontamination of air/water, ${ }^{[2,3]}$ antimicrobial materials, ${ }^{[4,5]}$ or photodynamic therapy (PDT). ${ }^{[6]}$ Singlet oxygen, a powerful oxidant produced by energy transfer from the photoactivated sensitizer to

C. Boussiron, Dr. M. Le Bechec, Dr. L. Petrizza, J. Sabalot,

Dr. S. Lacombe, Dr. M. Save

CNRS/Univ Pau \& Pays Adour/E2S UPPA, IPREM

Institut des Sciences Analytiques et de Physicochimie pour

l'Environnement et les Matériaux

UMR5254, Hélioparc, 2 av. P. Angot., 64000 Pau, France

E-mail: sylvie.lacombe@univ-pau.fr; maud.save@univ-pau.fr

The ORCID identification number(s) for the author(s) of this article can be found under https://doi.org/10.1002/marc.201800329.

DOI: $10.1002 /$ marc.201800329
Photosensitizers were mainly grafted onto cross-linked polymer beads, ${ }^{[7,8]}$ or involved in the synthesis of star-like polymers or block copolymer micelles for PDT. ${ }^{[9,10]}$ Few studies have reported the preparation of polymer films integrating the organic photosensitizer via a covalent bonding. ${ }^{[11-16]}$ Most of these studies required multi-step synthesis and the films were mostly prepared by organic solvent casting or more sporadically by melt compression molding. ${ }^{[17]}$ In that context, functional waterborne latex synthesized by the scalable emulsion polymerization process, is versatile to prepare photosensitizer-supported materials either as stable colloidal particles or as polymer film. The recent development of polymerization-induced self-assembly (PISA) offers new perspectives in the design of latex particles by surfactant-free emulsion ${ }^{[18]}$ or dispersion ${ }^{[19,20]}$ processes, up to a high solids content. The simultaneous self-assembly and particle growth enables the synthesis of well-defined core-shell spherical or anisotropic particles formed by self-assembled block copolymer chains. ${ }^{[18-21]}$ Moreover, the absence of molecular surfactant circumvents some detrimental effects of molecular surfactant like transparency loss. The first examples describing this strategy used poly(acrylic acid) as macromolecular control agent and stabilizer. ${ }^{[22,23]}$ More recently, Chenal et al. interestingly showed that poly(acrylic acid)-b-poly(n-butyl acrylate) 
(PAA- $b$-P $n$ BA) synthesized by emulsion PISA produced homogeneous and cohesive transparent polymer films. ${ }^{[2,25]}$ The percolating network of the thin high glass transition temperature $\left(T_{\mathrm{g}}\right)$ layer at low volume fraction was at the origin of these remarkable mechanical properties of the low $T_{\mathrm{g}}$ polymer film. Another study showed that the adsorption of PAA- $b$-PnBA diblock copolymer onto soft acrylic latex particles prior to their film formation also creates a percolating network that raises the elastic modulus, creep resistance, and tensile strength of the final film. ${ }^{[26]}$ For all these reasons, PAA and PnBA were chosen in the present work to synthesize light-responsive polymer particles and advanced films as substrate for supported photocatalysis. To the best of our knowledge, only one study has previously reported the copolymerization of a photosensitizer-based monomer in emulsion polymerization. ${ }^{[27]}$ In this study, non-film-forming cross-linked particles were synthesized by emulsion copolymerization of styrene, divinylbenzene, and $0.014 \mathrm{~mol} \%$ of tetrastyrylporphyrin. The yield of photo-oxidation of allylic alcohol casted on the particles was monitored in a minimum of organic solvent.

The originality of the present work relies on the copolymerization of two types of photosensitizer-based monomers with acrylic acid (AA) by reversible addition-fragmentation chain transfer (RAFT) polymerization in order to take advantage of the hydrophilic macromolecular chain transfer agent (macroCTA) to transpose the hydrophobic derivatized photosensitizer in the water phase. Emulsion PISA of $n \mathrm{BA}$ is expected to allow the direct synthesis of latex particles decorated with a photosensitizer covalently anchored in the hydrophilic shell surrounding the hydrophobic core (Scheme 1). The challenge is to design unique photoactive latex particles as platform for producing singlet oxygen from stable colloids dispersed in an aqueous phase while simultaneously offering the opportunity to produce advanced photosensitizing coatings by simple casting of the corresponding film-forming waterborne latex. The photoactivity in water of the different polymer materials (hydrophilic macroCTA, latex, and film) will be accurately compared via the determination of the quantum yields of singlet oxygen production under visible light irradiation.

The first step of the work consists in the synthesis of a photosensitizer-based monomer. Among the different organic photosensitizers, the commercially available Rose Bengal (RB) was chosen for its high quantum yield of singlet oxygen production $\left(\Phi_{\Delta}=0.76 \text { in water }\right)^{[28]}$ and its carboxylate functions allowing covalent grafting with halogenated substrates. ${ }^{[8,29]}$ Vinylbenzyl Rose Bengal (VBRB) was first synthesized by nucleophilic substitution of Rose Bengal with 4-vinylbenzyl chloride (Figure S1, Supporting Information). The successful covalent bonding of the chromophore with vinylbenzyl chloride was confirmed by NMR (Figure S2, Supporting Information) and by the slight bathochromic shift of the maximum of absorbance and emission spectra (Figure S3, Supporting Information). RAFT copolymerization of AA with $0.5 \mathrm{~mol} \%$ of VBRB was carried out at $80{ }^{\circ} \mathrm{C}$ mediated by the trithiocarbonate CTA (Expt. 3 in Table S1, Supporting Information). Based on a previous study of Loiseau et al., ${ }^{[30]}$ 1,4-dioxane was chosen as solvent of polymerization as it proved to be less prone to irreversible transfer reaction for RAFT polymerization of AA. Kinetics of RAFT polymerization was monitored by proton NMR and was compared to the kinetics of AA RAFT homopolymerization under similar experimental conditions (Expt. 1 and 3 in Table S1, Supporting Information). Note that the previous studies dealing with free radical copolymerization of VBRB with vinylic monomers have never investigated any polymerization kinetics. ${ }^{[29]}$ While the AA polymerization exhibited a linear evolution of the logarithmic monomer conversion versus time and complete conversion within $3 \mathrm{~h}$ (Figure 1), $0.5 \mathrm{~mol} \%$ of VBRB induced polymerization inhibition with less than $7 \%$ of monomer conversion. Similar inhibition was observed for a polymerization carried out in dark (Expt. 4 in Table S1, Supporting Information). For the sake of comparison, RAFT copolymerization of AA with 0.5 mol\% of free RB was performed and the kinetics perfectly overlay with AA polymerization. Thus, the photoactive RB moiety alone did not alter the kinetics of AA polymerization mediated by the trithiocarbonate CTA. A novel Rose Bengal-based monomer, the 2-Rose Bengal ethyl acrylate (RBEA, Scheme 1), was synthesized via a two-step procedure through the synthesis of 2-bromoethylacrylate (Figure S4, Supporting Information). Both proton NMR spectra of the purified RBEA (Figure S5, Supporting Information) and the comparison of UV-visible absorbance/emission spectra with free RB (Figure S6, Supporting Information) confirmed its successful synthesis. Contrary to VBRB monomer, $0.5 \mathrm{~mol} \%$ of RBEA did not inhibit the AA RAFT polymerization (see Figure 1a) but a retardation was observed as the conversion at $6 \mathrm{~h}$ reached $48 \%$ against 93\% for AA homopolymerization (see Expts. 1 and 5 in Table S1, Supporting Information). A similar retardation phenomenon was observed for the copolymerization of AA with $0.25 \mathrm{~mol} \%$ of RBEA targeting a higher degree of polymerization, that is, for a similar value of the $[\mathrm{RBEA}]_{0} /[\mathrm{ACPA}]_{0}$ ratio (Figure S7, Supporting information). Polymerization kinetics were monitored with two lower fractions of RBEA (0.05 and $0.1 \mathrm{~mol} \%$ ) in order to decrease the molar ratio between the RB monomer and the ACPA initiator from 3.4 to 0.7 or 0.3 (Expts. 6 and 8 in Table S1, Supporting Information). The copolymerization kinetics with the lowest fraction of RBEA perfectly overlay with RAFT homopolymerization of AA (Figure 1a). For the AA copolymerization with $0.1 \mathrm{~mol} \%$ of RBEA, the initial polymerization rate was similar to AA homopolymerization but the loss of linearity observed above $60 \%$ of monomer conversion reveals a decrease of the apparent polymerization rate due to irreversible termination or transfer reactions. The extent of such side reactions remains quite low as the number-average molar mass $\left(M_{n}\right)$ was found to increase linearly with monomer conversion, close to the theoretical $M_{\mathrm{n}}$, and with dispersity below 1.4, in good agreement with AA homopolymerization (Figure 1b). Only a slight deviation from theoretical $M_{\mathrm{n}}$ trend was observed above $70 \%$ of conversion associated with a slight increase of dispersity from 1.3 to 1.4 . The copolymerization of VBRB with AA was thus performed at a lower $[\mathrm{RBEA}]_{0} /[\mathrm{ACPA}]_{0}$ ratio corresponding to $0.1 \mathrm{~mol} \%$ of VBRB (Expt. 7 in Table S1, Supporting Information). Exceeding an inhibition period of $50 \mathrm{~min}$, the RAFT copolymerization proceeded up to $85 \mathrm{~mol} \%$ (Figure 1a). Polymerization kinetics suggests that the presence of RB monomer might induce radical side reactions which do not significantly alter the RAFT polymerization of AA for ratio of RB-moieties versus the initiator below unity. For higher content of RB monomer, VBRB obviously induced inhibition of AA RAFT polymerization while only retardation was observed 
<smiles>C=CC(=O)OCc1ccc(CCl)cc1</smiles>

AA<smiles>COC(=O)c1c(Cl)c(Cl)c(Cl)c(Cl)c1-c1c2cc(I)c(=O)c(I)c-2oc2c(I)c(O[N+](=O)[O-])c(I)cc12</smiles>

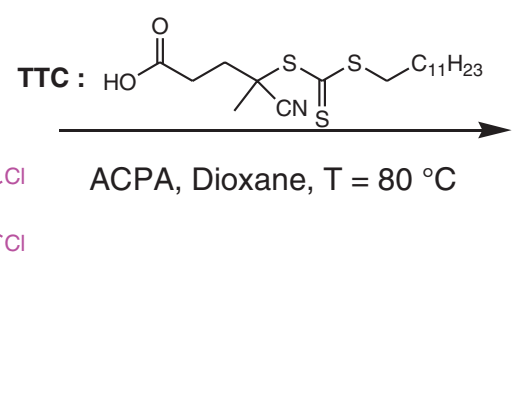
ACPA, Dioxane, $\mathrm{T}=80^{\circ} \mathrm{C}$

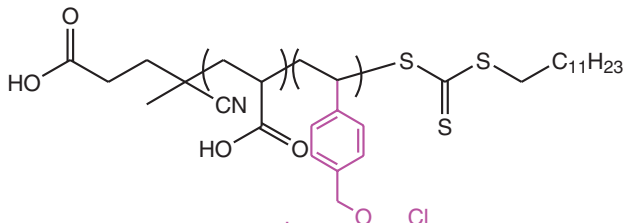

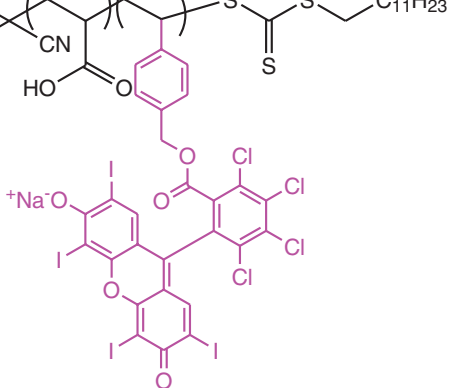<smiles>C=CC(=O)O</smiles>

AA<smiles>C=CC(=O)OCCOC</smiles><smiles>COC(=O)c1c(Cl)c(C)c(Cl)c(Cl)c1-c1c2cc(I)c(=O)c(I)c-2oc2c(I)c(O[N+]([O-])(O)O)c(I)cc12</smiles>

RBEA

0.05-0.5 mol\%
ACPA, water/ $\mathrm{NH}_{4} \mathrm{OH}, \mathrm{pH} 5.4$ $\mathrm{T}=70^{\circ} \mathrm{C}$

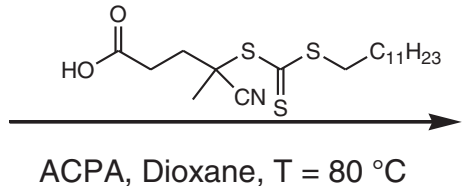<smiles>CCCCCCCCCCCC(C)(C)CC(CC(C)(C)C(=O)OC)C(=O)O</smiles>
macro-CTA

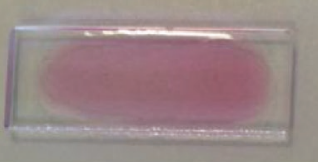

Polymer film

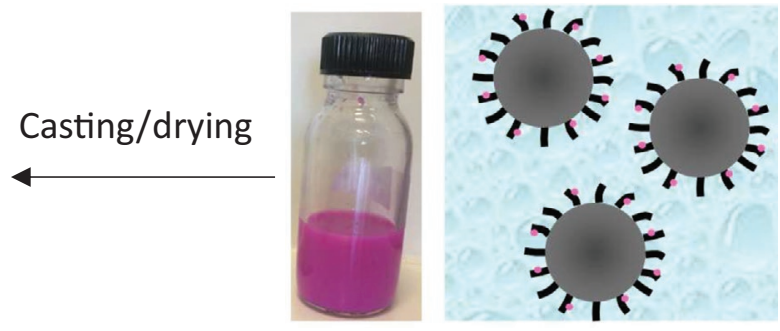

Waterborne PnBA Latex with photosensitizer-functionalized PAA shell

$$
\begin{aligned}
& \text { Irradiation } \lambda_{\text {LED }}=515 \mathrm{~nm} \\
& \underset{\mathrm{O}}{\stackrel{\mathrm{H}_{2} \mathrm{O}}{\longrightarrow}} \mathrm{HOH}-\overrightarrow{\mathrm{O}}=\mathrm{O}
\end{aligned}
$$

\section{6 -hydroxy- $(2 \mathrm{H})$}

Scheme 1. RAFT copolymerization of VBRB or RBEA with AA and synthesis of photoactive latex particles by emulsion polymerization of $n B A$ using of the photosensitizer-grafted hydrophilic macro-CTA. Photo-oxygenation of furfuryl alcohol by in situ produced singlet oxygen.

for RBEA copolymerization. It can be mentioned that the NMR monitoring of both monomers at $115^{\circ} \mathrm{C}$ highlighted that VBRB degraded into a vinylbenzyl side product while RBEA remained stable at such temperature (Figure S8, Supporting Information). This degradation is thermally activated as the extent of side products for VBRB is more difficult to probe by NMR at lower temperature of $80{ }^{\circ} \mathrm{C}$. A shielding of the methylene of the benzyl group from 5.0 to $4.7 \mathrm{ppm}$ is observed in the side product of VBRB, which could be associated, for instance, with the formation of (4-Vinyl-phenyl)-methanol. The understanding of this phenomenon will be the subject of a further study that is beyond the scope of this communication. Thus, PAA macro-CTA including RBEA comonomer will be selected to perform PISA emulsion polymerization of $n$-butyl acrylate. The overlay of both size exclusion chromatography (SEC) traces recorded by refractometer and UV-visible detector set at $\lambda=$ $570 \mathrm{~nm}$, the characteristic wavelength of RB units, confirmed the successful copolymerization of RBEA with AA (Figure S9, Supporting Information). The photosensitizer is well anchored to the hydrophilic macro-CTA to enable the design of photoactive latex particles.

One of the prerequisites for the successful synthesis of stable latex by PISA is to achieve a high level of chain end functionalization for the hydrophilic polymer that should promote the in situ synthesis of amphiphilic block copolymer by controlled radical polymerization. The UV-visible spectrum of 

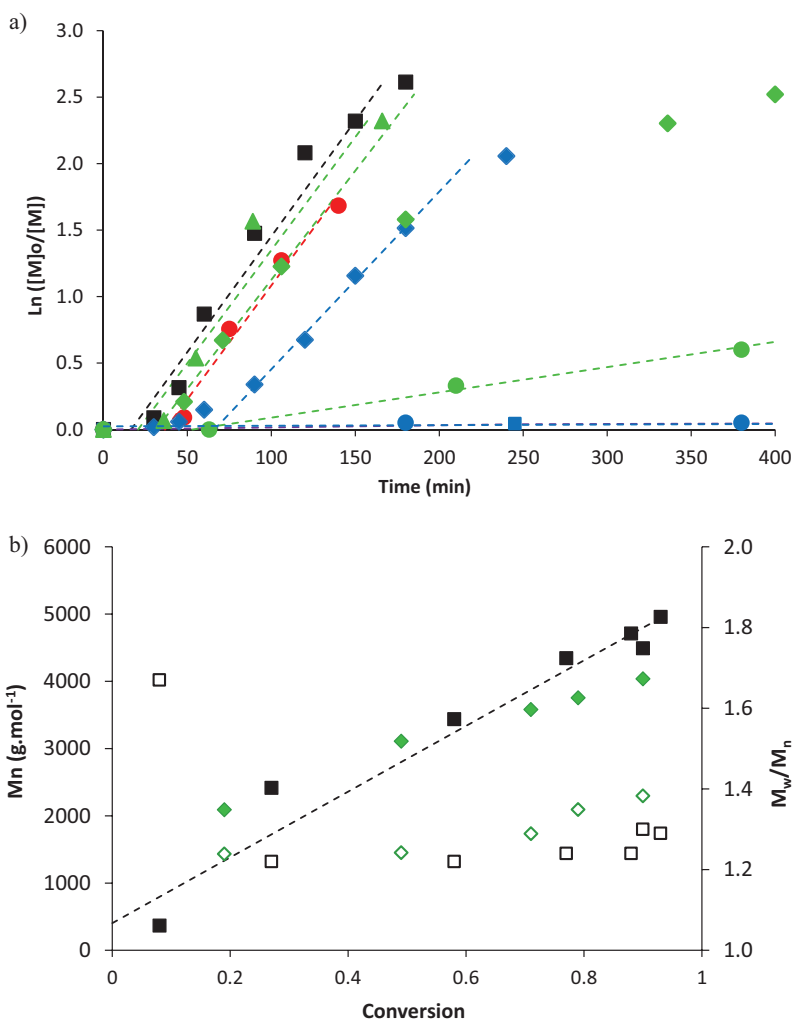

Figure 1. a) Semilogarithmic plots of monomer conversion versus time for AA polymerization $(\square)$ absence of RB derivatives (Expt. 1), (O) free RB (Expt. 2), (O) 0.5 mol\% VBRB (Expt. 3), ( $\square 0.5$ mol\% VBRB (Expt. 4 in dark), (O) 0.5 mol\% RBEA (Expt. 5), ( ) 0.1 mol\% RBEA (Expt. 6), ( $\diamond) 0.1 \mathrm{~mol} \%$ VBRB (Expt. 7), ( 4 ) 0.05 mol\% RBEA (Expt. 8). b) $M_{n}$ (filled symbols) and dispersity (open symbols) versus conversion. The dotted line corresponds to the theoretical trend of $M_{n}$. Experiments of Table S1, Supporting Information.

the precipitated $\mathrm{P}(\mathrm{AA}-\mathrm{co}-\mathrm{RBEA})$ macro-CTA clearly indicated the presence of the trithiocarbonate chain end at $\lambda=309 \mathrm{~nm}$ at a similar extent than for the PAA synthesized by RAFT polymerization (Figure S10, Supporting Information). On the basis of the molar extinction coefficient of the trithiocarbonate $\left(\varepsilon_{\mathrm{TTC}}=11285 \mathrm{~L} \mathrm{~mol}^{-1} \mathrm{~cm}^{-1}\right.$ in ethanol $)$ and $M_{\mathrm{n}}$ value of PAA and $\mathrm{P}(\mathrm{AA}-\mathrm{co}-\mathrm{RBEA})$, we calculated an average of 0.9 TTC per polymer chain, which confirms the polymer livingness. This is based on the hypothesis that free and polymer-bound trithiocarbonate have a similar molar extinction coefficient. RAFT emulsion polymerization of $n \mathrm{BA}$ was carried out at $70{ }^{\circ} \mathrm{C}$ using $\mathrm{P}\left(\mathrm{AA}-\mathrm{co}-\mathrm{RBEA}_{0.25 \mathrm{~mol} \%}\right)$ as macro-CTA and 4,4'-Azobis(4cyanopentanoic acid) (ACPA) as initiator. A complete monomer conversion was reached for the latex prepared at $23 \mathrm{wt} \%$ of solids content and $\mathrm{pH}$ of 5.4 (Table S2, Supporting Information). Dynamic light scattering measurements indicated the formation of narrowly dispersed $85 \mathrm{~nm}$ latex particles with dispersity of 0.07 (Figure 2). The latex was free of coagulum and stable over weeks. The SEC analysis confirmed the formation of block copolymer with a shift of the chromatogram toward higher molar masses (Figure S11, Supporting information). As expected the copolymer, mainly constituted of $\mathrm{P} n \mathrm{BA}$, exhibited a low glass transition temperature $\left(T_{\mathrm{g}} \approx-43^{\circ} \mathrm{C}\right.$, Figure $\mathrm{S} 12$, Supporting Information). The aqueous dispersion of P(AA-co$\mathrm{RBEA}_{0.25 \mathrm{~mol} \%}$ )- $b$-PnBA particles was casted onto a glass slide and dried to prepare the polymer film (Scheme 1). The transparent films were analyzed by UV-visible spectroscopy in water and compared with free RB, P(AA-co-RBEA) macro-CTA, and $\mathrm{P}$ (AA-co-RBEA)- $b$-PnBA latex in the characteristic range of absorbance of RB-moiety ( $\lambda=450-600 \mathrm{~nm}$, Figure 2$)$. The normalized absorbance spectra of the polymeric materials perfectly overlay and exhibit the characteristic shape of Rose Bengal. The absence of both additional band or variation of the relative intensity of the two bands proves the absence of RB aggregation. ${ }^{[31]}$ The bathochromic shift compared to free RB is characteristic of the covalent bonding of $\mathrm{RB}$ with the macro-CTA and accordingly with the block copolymer particles and polymer film. The polymer film was immersed in water for $24 \mathrm{~h}$ and the absorbance of the continuous phase was analyzed in order to control the level of any chemical leaching from the film. As reported in Figure S13, Supporting Information, no characteristic signal of RB moiety at $565 \mathrm{~nm}\left(\varepsilon_{\mathrm{RB}}=113000 \mathrm{~L}\right.$ $\mathrm{mol}^{-1} \mathrm{~cm}^{-1}$ ) was observed in the aqueous solution and very low level of absorbance (Abs $<0.02)$ is observed at the wavelength
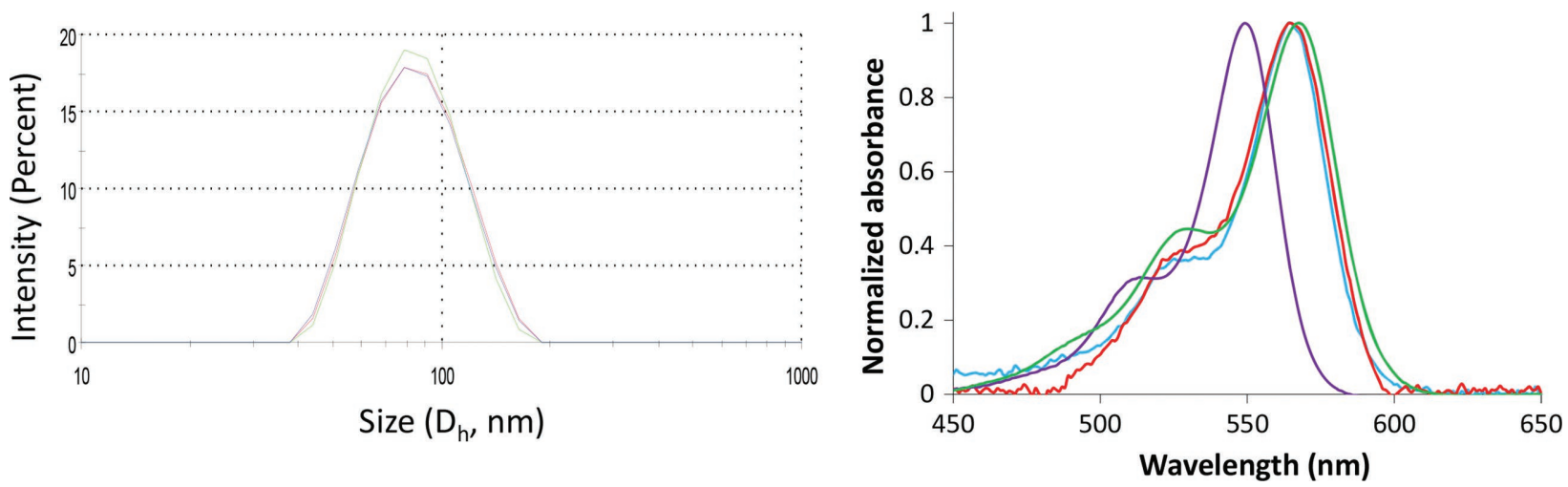

Figure 2. Left) Particle size distribution of the $P\left(A A-c o-R B E A_{0.25 m o l}\right)$-b-PnBA latex; Right) Overlay of normalized absorbance spectra $(\lambda=450-650$ nm) in water: (purple) free Rose Bengal, (blue) precipitated P(AA-co-RBEA 0.1 mol\%)-TTC macromolecular RAFT agent (Expt. 6 in Table S1, Supporting Information), (red) PnBA latex synthesized from the P(AA-co-RBEA 0.25 mol\%)-TTC (see Table S2, Supporting Information), (green) polymer film from RB-latex casting. 
of the trithiocarbonate $309 \mathrm{~nm}\left(\varepsilon_{\text {TTC }}=11285 \mathrm{~L} \mathrm{~mol}^{-1} \mathrm{~cm}^{-1}\right)$, which confirms the anchorage of RB-based macro-CTA with the particles.

To examine the photoactivity of the various polymers, the $\mathrm{P}(\mathrm{AA}-\mathrm{co}$-RBEA) macro-CTA as well as the latex and film based on $\mathrm{P} n \mathrm{BA}$, we undertook the measurements of singlet oxygen quantum yield $\left(\varnothing_{\Delta}^{\text {Sens }}\right)$ which corresponds to the number of singlet oxygen molecules produced by number of absorbed photons. The singlet oxygen quantum yields were determined in water under irradiation at $515 \mathrm{~nm}$ by chemical quenching of the well-known probe, furfuryl alcohol (FFA) oxidized to 6-hydroxypyran-3-one (Scheme 1). The values of $\varnothing_{\Delta}^{\text {Sens }}$ for the sensitizer grafted onto the polymers were obtained by comparative experiments according to Equation (1), relative to that of free Rose Bengal $\left(\varnothing_{\Delta}^{\mathrm{RB}}=0.76\right)^{[28]}$ (see more details of calculation in Supporting Information).

$\varnothing_{\Delta}^{\mathrm{Sens}}=\varnothing_{\Delta}^{\mathrm{RB}} \frac{P_{\mathrm{a}}^{\mathrm{RB}}}{P_{\mathrm{a}}^{\mathrm{Sens}}} \frac{r_{\mathrm{ox}}^{\mathrm{Sens}}}{r_{\mathrm{ox}}^{\mathrm{RB}}}$

In Equation (1), $r_{\mathrm{ox}}$ corresponds to the rate of disappearance of the quencher by reaction with singlet oxygen $\left(\mathrm{mol} \mathrm{L} \mathrm{L}^{-1}\right.$ $\min ^{-1}$ ) and $P_{\mathrm{a}}$ is the photon flux absorbed by the sensitizer (Einstein $\mathrm{L}^{-1} \mathrm{~s}^{-1}$ ). It is interesting to note that $\mathrm{PnBA}$ latex particles synthesized by PISA from P(AA-co-RBEA)-TTC reactive stabilizer are highly efficient to promote oxidation under irradiation as revealed by the high value of singlet oxygen quantum yield $\left(\varnothing_{\Delta}^{\text {Sens }}=0.61\right.$, Table 1$)$. Only one study has previously reported the covalent coupling of a photosensitizer with poly(alkyl acrylate). ${ }^{[32]}$ The poly(acrylic acid-co-ethylhexyl acrylate) was associated with values of $\varnothing_{\Delta}^{\text {Sens }}$ equal to 0.20 in dimethylformamide solvent. ${ }^{[32]}$ We measured $\varnothing_{\Delta}^{\text {Sens }}$ for both macro-CTAs in water. The values are in a similar range $(0.19$ 0.26 , Table 1) whatever the RB loading but lower than for the final latex. Despite the absence of RB aggregation revealed by the shape of the absorbance spectra (Figure 2), the conformation of the macro-CTA might be different in water than on the nanoparticle surface. The number of $\mathrm{P}(\mathrm{AA}-\mathrm{co}-\mathrm{RBEA})$ chains at

Table 1. Quantum yield of singlet oxygen production in water from the macro-RAFT, latex, and film covalently bonded with RB.

\begin{tabular}{|c|c|c|c|}
\hline Sample & $\begin{array}{l}\text { RB loadinga) } \\
{\left[\mu \mathrm{mol} \mathrm{g}{ }^{-1}\right]}\end{array}$ & $\begin{array}{l}\text { Sample }{ }^{\mathrm{b})} \\
{\left[\mathrm{g} \mathrm{L}^{-1}\right]}\end{array}$ & $\phi_{\Delta(\mathrm{H} 2 \mathrm{O})}$ \\
\hline RB & 983 & 0.99 & 0.76 \\
\hline $\mathrm{P}\left(\mathrm{AA}-\mathrm{co}-\mathrm{RBEA} \mathrm{A}_{0.05 \mathrm{~mol} \%}\right)-\mathrm{TTC}$ & 3.3 & 0.12 & 0.19 \\
\hline $\mathrm{P}\left(\mathrm{AA}-c o-\mathrm{RBEA}_{0.1 \mathrm{~mol} \%)-\mathrm{TTC}}\right.$ & 6.3 & 0.06 & 0.26 \\
\hline 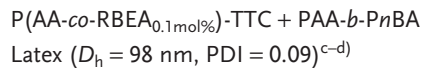 & 0.3 & $0.07+1.64$ & 0.60 \\
\hline 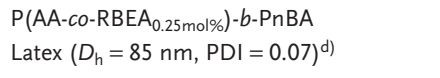 & 0.3 & 1.60 & 0.61 \\
\hline RB-Latex Film & 0.3 & - & 0.16 \\
\hline
\end{tabular}

a) The loading of RBEA monomer into the macro-CTA and latex is calculated as follows: Loading $=n_{\mathrm{RBEA}} / m_{\text {polymer }}=\left[(\right.$ Abs $\left.\times V) /\left(\varepsilon_{\mathrm{RB}} \times L\right)\right] / m_{\text {polymer }}$ with $L=1 \mathrm{~cm}$ and $\varepsilon=113000 \mathrm{~L} \mathrm{~mol}^{-1} \mathrm{~cm}^{-1}$ the molar extinction coefficient of Rose Bengal in water at $\lambda=551 \mathrm{~nm}$; ${ }^{\text {b) }}$ Concentration of the samples used for singlet oxygen measurements; ${ }^{c}$ The non-functionalized latex was synthesized from a PAA-TTC macro-CTA

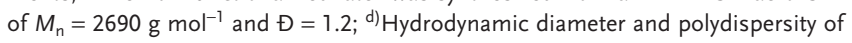
latex particles measured by DLS. the surface of the colloidal particles was estimated at 0.04 chain $\mathrm{nm}^{-2}$ based on the initial number of moles of macro-CTA and the overall surface calculated from the particle diameter and the number of particles (Table S2, Supporting Information). Such polymer density corresponds to a semi-dilute regime in which the polymer chains are more constrained than in the mushroom regime, the latter being generally observed for grafting density lower than 0.01 chain $\mathrm{nm}^{-2} \cdot{ }^{[33]}$ It has been previously shown that the polymer conformation can affect the photoactivity of grafted organic photosensitizers, ${ }^{[34]}$ which might explain the difference observed between efficiency of RB-based PAA in water or on the surface of the colloidal particles. In order to investigate whether the latex particles could influence ${ }^{1} \mathrm{O}_{2}$ production, the value of $\phi_{\Delta}$ of $\mathrm{P}\left(\mathrm{AA}-\mathrm{co}-\mathrm{RBEA}_{0.1 \mathrm{~mol} \%}\right)$ macroCTA was measured in the presence of non-functionalized PAA$b$-P $n$ BA latex particles. It should be noted that the baseline deviation of the UV-visible spectra, observed only in the presence of particles, is systematically corrected by a polynomial fit to limit the overestimation of the RB absorbance arising from light scattering (see Figure S15, Supporting Information). An increase of $\phi_{\Delta}$ of the $\mathrm{P}\left(\mathrm{AA}-\mathrm{co}-\mathrm{RBEA}_{0.1 \mathrm{~mol} \%}\right)$ macro-CTA from 0.26 to 0.60 was observed (Table 1 ), which might be ascribed either to an effect of the light scattered by the particles on ${ }^{1} \mathrm{O}_{2}$ production and/or to an impact of the particles on the quencher or oxygen distribution in the medium. This result raises a scientific point to be explored in the near future. The novel photoactive waterborne core-shell latex synthesized by PISA (Table 1 and Table S2, Supporting Information) are efficient to form photoactive transparent films from simple casting and drying steps of the aqueous colloidal dispersion (see the picture in Scheme 1). Indeed, under the same experimental conditions used for latex particles and macro-CTA, the clear decrease of FFA concentration in the presence of the polymer film proved the efficient production of singlet oxygen at the film interface (Figure S14, Supporting Information). An estimated value of $\varnothing_{\Delta}^{\text {Sens }}$ of 0.16 was calculated (Table 1 ) but we would like to draw attention that this value should be taken with care as there are several difficulties to accurately measure $\varnothing_{\Delta}^{\text {Sens }}$ for solid photosensitizing materials. ${ }^{[35]}$ Both light scattering effects and accurate measurement of the number of absorbed photons by the active photosensitizer make the determination of singlet oxygen quantum yield a difficult task.

In conclusion, we developed novel photosensitizer-grafted film-forming latex particles with high potential to form advanced functional coatings exhibiting photo-oxidation activity under visible light. The photosensitizer-grafted polymer colloids fulfilled interesting specifications like an eco-friendly synthesis by emulsion polymerization performed in aqueous dispersed media, the absence of molecular surfactants, and an easy casting process to prepare photoactive polymer films. PISA of $n$-butyl acrylate proved to be an efficient method to produce stable submicronic core-shell particles with the hydrophilic outer shell directly functionalized by the organic photosensitizer through the macro-CTA synthesized by RAFT copolymerization of AA and 2-RBEA. The present work also investigated the impact of the comonomer structure on the RAFT polymerization of AA, highlighting a lower inhibition with 2-RBEA compared to VBRB. Interestingly the three types of synthesized polymers (hydrophilic polymer, latex particles, and 
polymer film) proved to be photoactive with the colloidal dispersion of particles being the most efficient to produce singlet oxygen $\left(\varnothing_{\Delta}^{\text {Sens }}=0.6\right)$.

\section{Experimental Section}

All the experimental information is provided in Supporting Information.

\section{Supporting Information}

Supporting Information is available from the Wiley Online Library or from the author.

\section{Acknowledgements}

The authors would like to thank Agence Nationale de la Recherche (ANR) for funding FUNPOLYSURF project (ANR-15-CE08-0005-01), CNRS and UPPA for financial support. The authors would also like to thank Abdel Khoukh and Elise Deniau for their support, respectively, in NMR and DLS techniques. Amelie Vax (LCPO, University of Bordeaux) is acknowledged for running analysis by SEC DMF with UV-visible detector.

\section{Conflict of Interest}

The authors declare no conflict of interest.

\section{Keywords}

colloids, emulsion polymerization, films, reversible addition fragmentation chain transfer, photosensitization, singlet oxygen

Received: April 30, 2018

Revised: June 15, 2018

Published online:

[1] S. Triemer, K. Gilmore, G. T. Vu, P. H. Seeberger, A. SeidelMorgenstern, Angew. Chem. Int. Ed. Engl. 2018, 130, 5623-5626, https://doi.org/10.1002/ange.201801424

[2] E. Diez-Mato, F. C. Cortezon-Tamarit, S. Bogialli, D. Garcia-Fresnadillo, M. D. Marazuela, Appl. Catal. B 2014, 160, 445.

[3] M. L. Marin, L. Santos-Juanes, A. Arques, A. M. Amat, M. A. Miranda, Chem. Rev. 2012, 112, 1710.

[4] F. Vatansever, W. C. M. A. de Melo, P. Avci, D. Vecchio, M. Sadasivam, A. Gupta, R. Chandran, M. Karimi, N. A. Parizotto, R. Yin, G. P. Tegos, M. R. Hamblin, FEMS Microbiol. Rev. 2013, 37, 955.

[5] K. Page, M. Wilson, I. P. Parkin, J. Mater. Chem. 2009, 19, 3819.
[6] Z. Zhou, J. Song, L. Nie, X. Chen, Chem. Soc. Rev. 2016, 45, 6597.

[7] S. Ribeiro, A. C. Serra, A. M. d. A. Rocha Gonsalves, ChemCatChem 2013, 5, 134

[8] M. Isabel Burguete, R. Gavara, F. Galindo, S. V. Luis, Catal. Commun. 2010, 11, 1081.

[9] H. Jin, X.-H. Dai, C. Wu, J.-M. Pan, X.-H. Wang, Y.-S. Yan, D.-M. Liu, L. Sun, Eur. Polym. J. 2015, 66, 149.

[10] Y. Sun, H. Hu, N. Zhao, T. Xia, B. Yu, C. Shen, F.-J. Xu, Biomaterials 2017, $117,77$.

[11] L. Pessoni, S. Lacombe, L. Billon, R. Brown, M. Save, Langmuir 2013, 29, 10264

[12] A. Felgentraeger, T. Maisch, A. Spaeth, J. A. Schroeder, W. Baeumler, PCCP 2014, 16, 20598.

[13] C. Piccirillo, S. Perni, J. Gil-Thomas, P. Prokopovich, M. Wilson, J. Pratten, I. P. Parkin, J. Mater. Chem. 2009, 19, 6167.

[14] A. M. Ferreira, I. Carmagnola, V. Chiono, P. Gentile, L. Fracchia, C. Ceresa, G. Georgiev, G. Ciardelli, Surf. Coat. Technol. 2013, 223, 92.

[15] M. Krouit, R. Granet, P. Krausz, Eur. Polym. J. 2009, 45, 1250.

[16] W. C. Zhou, S. Begum, Z. B. Wang, P. Krolla, D. Wagner, S. Brase, C. Woll, M. Tsotsalas, ACS Appl. Mater. Interfaces 2018, 10, 1528.

[17] K. Zerdin, M. A. Horsham, R. Durham, P. Wormell, A. D. Scully, React. Funct. Polym. 2009, 69, 821.

[18] B. Charleux, G. Delaittre, J. Rieger, F. D'Agosto, Macromolecules 2012, 45, 6753 .

[19] J. Rieger, Macromol. Rapid Commun. 2015, 36, 1458.

[20] N. J. Warren, S. P. Armes, J. Am. Chem. Soc. 2014, 136, 10174.

[21] Y. Pei, A. B. Lowe, P. J. Roth, Macromol. Rapid Commun. 2017, 38, 1600528.

[22] G. Delaittre, J. Nicolas, C. Lefay, M. Save, B. Charleux, Chem. Commun. 2005, 614.

[23] C. J. Ferguson, R. J. Hughes, B. T. T. Pham, B. S. Hawkett, R. G. Gilbert, A. K. Serelis, C. H. Such, Macromolecules 2002, 35, 9243.

[24] M. Chenal, J. Rieger, C. Vechambre, J.-M. Chenal, L. Chazeau, C. Creton, L. Bouteiller, Macromol. Rapid Commun. 2013, 34, 1524.

[25] M. Chenal, C. Vechambre, J.-M. Chenal, L. Chazeau, V. Humblot, L. Bouteiller, C. Creton, J. Rieger, Polymer 2017, 109, 187.

[26] R. S. Gurney, A. Morse, E. Siband, D. Dupin, S. P. Armes, J. L. Keddie, J. Colloid Interface Sci. 2015, 448, 8.

[27] A. G. Griesbeck, T. T. El-Idreesy, A. Bartoschek, Adv. Synth. Catal. 2004, 346, 245.

[28] F. Wilkinson, W. P. Helman, A. B. Ross, J. Phys. Chem. Ref. Data 1993, 22, 113.

[29] M. Nowakowska, M. Kepczynski, K. Szczubialka, Pure Appl. Chem. 2001, 73, 491.

[30] J. Loiseau, N. Doerr, J. M. Suau, J. B. Egraz, M. F. Llauro, C. Ladaviere, Macromolecules 2003, 36, 3066.

[31] J. Paczkowski, D. C. Neckers, Macromolecules 1985, 18, 1245.

[32] F. Amatguerri, J. M. Botija, R. Sastre, J. Polym. Sci. Part A: Polym. Chem. 1993, 31, 2609.

[33] Y. Tsujii, K. Ohno, S. Yamamoto, A. Goto, T. Fukuda, in SurfaceInitiated Polymerization I, Vol. 197 (Ed: R. Jordan), Springer, Berlin 2006, p. 1.

[34] P. Liu, C. Yue, Z. Sheng, G. Gao, M. Li, H. Yi, C. Zheng, B. Wang, L. Cai, Polym. Chem. 2014, 5, 874.

[35] D. E. Wetzler, D. Garcia-Fresnadillo, G. Orellana, PCCP 2006, 8, 2249. 